\title{
Modelling the impacts of challenging 2030 DPRK's GHGs mitigation targets on DPRK's energy system
}

\author{
Yongjae $\mathrm{An}^{1,2}$, Haijun $\mathrm{Cao}^{1}$, Cholu Kwon ${ }^{2}$ \\ ${ }^{1}$ School of Humanities and Law, Northeastern University, Shenyang, China \\ ${ }^{2}$ Institute of Development Strategy of Science and Technology, State Academy of Sciences, Pyongyang, DPR Korea
}

\begin{abstract}
The DPRK ratified the Paris Agreement on 1st August 2016 and fully committed to achieving goals for reduction of greenhouse gas (GHG) in its Intended Nationally Determined Contribution (INDC) which was submitted on 3rd October 2016. The DPRK's INDC includes a mitigation and an adaptation component. In the mitigation component, as unconditional contribution, DPRK intends to achieve with domestic resources the reduction of GHG emissions by $8 \%$ by 2030 as compared to Business as Usual (BAU) scenario. Moreover, the conditional contributions are measures that could be implemented if additional international financial support, technology transfer and capacity building are received. The national contribution could be increased up to $40 \%$ with international support. This paper focuses on these mitigation targets for DPRK by an interesting case study of GHG emissions for a 12 year period from 1990 to 2002. We proposed the DPRK's GHGs mitigation model by analyzing the Irish TIMES (The Integrated MARKAL-EFOM System) energy systems modelling tool, and proved the technical availability of CO2-8 scenario delivering an $8 \%$ emissions reduction target by 2030 . We then compared the scenario results in terms of changes in energy technology, the role of energy efficiency and renewable energy.
\end{abstract}

\section{Introduction}

DPRK has recently made great progress in the implementation of the forest restoration campaign, thus has achieved a great success in establishing the sufficient material and technical basis for national environment protection, afforestation and enclosing-with-park throughout the country. In addition, large or medium and small hydropower stations, including the Paektusan Hero Youth Power Station, have been built, which has made great progress in improving power generation and consumption efficiency and expanding the use of renewable energy. All these efforts have made some progress in protecting environment. Many scientific and technological advances including the circular production system of the agricultural sector and zero-energy, zerocarbon structure of the construction sector have promoted the sustainable development of social and economic sectors. In addition, the DPRK has also established a legal policy framework to deal with climate change, supplemented the Environmental Protection Law with the contents related to climate change, and promulgated a new Environment Impact Assessment Law. In particular, in order to promote the efforts of the international community to address climate change, DPR Korea ratified the UNFCCC (an acronym for the United Nations Framework Convention on Climate Change) on 5 December 1994, the Kyoto Protocol on 27 April 2005 and the Paris Agreement on 1 August 2016[1].
DPR Korea is now making progress towards initiating the enabling activities to prepare the Third National Communication and the First Biennial Update Report under international support.

Integrating climate change considerations into relevant socio-economic development strategies and plans is considered as one of the important measures to ensure the sustainable development in DPR Korea. In particular, in accordance with the five-year development strategy of the national economy, national energy and climate change issues are simultaneously to be addressed by improving the efficiency of electric power generating facilities and by scaling up the utilization of renewable energy.

In accordance with decisions 1/CP.19, 1/CP.20 and 1/CP.21 of the Conference of the Parties to UNFCCC, the DPRK government has prepared the INDC, which also includes a mitigation and an adaptation.

The mitigation component includes both unconditional and conditional contributions. The unconditional contributions are measures that will be implemented using domestic resources. With domestic resources, GHG emissions will be reduced by $8.0 \%$ by 2030 compared to the BAU scenario. The conditional contributions are measures that could be implemented if additional international financial support, technology transfer and capacity building are received. The national contribution could be increased up to $40.25 \%$ with international support by 2030(Table 1) 
Table 1. Contribution to DPR Korea's GHGs Mitigation by 2030

\begin{tabular}{|c|c|}
\hline \multicolumn{2}{|c|}{ BAU Scenario } \\
\hline $\begin{array}{r}\text { DPR Korea's BAU scenario for GHG } \\
\text { assumption of economic growth in the abs } \\
-\quad \text { GHG emission projectio } \\
-\quad \text { GHG emission projectio }\end{array}$ & $\begin{array}{l}\text { missions was developed based on the } \\
\text { nce of climate change policies. } \\
\text { s for 2020: } 116.36 \text { million } \mathrm{tCO} 2 \mathrm{e} \\
\text { is for 2030: } 187.73 \text { million } \mathrm{tCO} 2 \mathrm{e}\end{array}$ \\
\hline Unconditional contribution & Conditional contribution \\
\hline $\begin{array}{l}\text { Based the on national circumstances, } \\
\text { common but differentiated responsibility } \\
\text { and its capability, DPR Korea will reduce } \\
\text { GHG emissions by } 8.0 \% \text { compared to } \\
\text { BAU scenario, by } 2030 \text { with domestic } \\
\text { resources. }\end{array}$ & $\begin{array}{l}\text { DPR Korea could achieve the additional } \\
\text { contribution equivalent to } 32.25 \% \text { of the } \\
\text { GHG emission in the BAU scenario by } 2030 \\
\text { if international support is received through } \\
\text { international cooperation including the } \\
\text { financial support under the Paris Agreement. }\end{array}$ \\
\hline
\end{tabular}

The adaptation component describes the adaptation needs raised in terms of institutional arrangement, financing, capacity building and technology transfer by 2030. It also presents the prioritized adaptation measures.

According to the global innovation index (GII) ranking in 2018, Ireland ranks $10^{\text {th }}$ among 127 economies in the world [2]. Thus, they have explored a number of more effective energy modelling ways and experience in practice.

Ireland is an island country surrounded by the sea, so it has abundant water and wind resources. DPR Korea is also surrounded by the sea on three sides, with a total coastline of about $17,300 \mathrm{~km}(3,169 \mathrm{~km}$ for Ireland), so there are also abundant resources of hydropower, wave power, tidal energy and wind power. On the basis of these geographical conditions, we can take into account Ireland's energy system model to achieve "good model" for DPR Korea's energy system. Meanwhile, Ireland established the Ireland Energy Centre in 1994 to support the development of energy efficiency and energy management in all sectors of the national economy [3]. DPR Korea has research institutions of various central institutions, which are actively developing the introduction of environmentally sound technologies and constantly innovating. Under such favorable geographical conditions and research capacity, DPRK has made many achievements in environmental protection and new energy development in recent years, increasing energy efficiency and actively developing new energy. In this process, in order to establish a scientific energy system, it is urgent to construct energy system model that can ensure the complete and sustainable economic development [4].

The purpose of this paper is that the $\mathrm{CO} 2-8$ scenario for achieving the GHGs mitigation target in DPRK to 2030 can be technically achieved. Moreover, it is that develop a techno-economic energy model of DPRK to the year 2030. From a technical perspective, the particular focus is on the feasibility of an $8 \%$ GHG emissions reduction target for DPRK and on quantifying the costs associated with meeting such a target. In this paper, the partial equilibrium model is used to model the technical energy system scheme to achieve the emission

$\mathrm{ESC}($ energy system cost $)=(\mathrm{IC}($ investment costs $)+\mathrm{OMC}($ operation \& maintenance costs $)+$

IFC(the costs of imported fuels)) - EFC(the costs of exported fuels) VT(the residual value of technologies at the end of the horizon) ent in does not address the policy tools needed to implement the technical solutions or address behavioral challenges that need to be overcome. The paper focuses on energyrelated $\mathrm{CO} 2$ emissions but also takes into account the impacts of limited GHGs reductions potential in each sector (as energy, waste and so on) on the targets for the DPRK's energy system. Special attention will be given to the implications for renewable energy, energy efficiency and more broadly for the economy.

This paper is structured as follows. Section 2 describes the methodological approach based on the Irish TIMES model and introduces the DPR Korea's energy system model (the model's current focus is on GHG emissions) used to carry out this analysis. Section 2 also presents some of the key inputs such renewable sources assumptions and introduces the different scenarios modelled. Section 3 presents the results, comparing the different mitigation scenarios in terms of impacts on the energy system. Section 4 draws some conclusions, discussing the relevance and the enlightenment for the future energy system in DPRK.

\section{Method}

\subsection{Irish TIMES Model[5]}

TIMES is a widely applied linear programming tool supported by ETSAP (Energy Technology Systems Analysis Program), an Implementing Agreement of the International Energy Agency (IEA) [6]. TIMES is an economic model generator of local, national or multiregional energy systems, which provides a technologyrich basis for estimating the long-term energy dynamics. It is usually applied to the analysis of the whole energy sector, but it can also be applied to the detailed study of individual sectors. It takes into account the environment and many technical constraints in the whole time to maximize the total surplus, which is equivalent to minimizing the total discounted energy system cost. This cost includes various costs over the period using the following formula: 


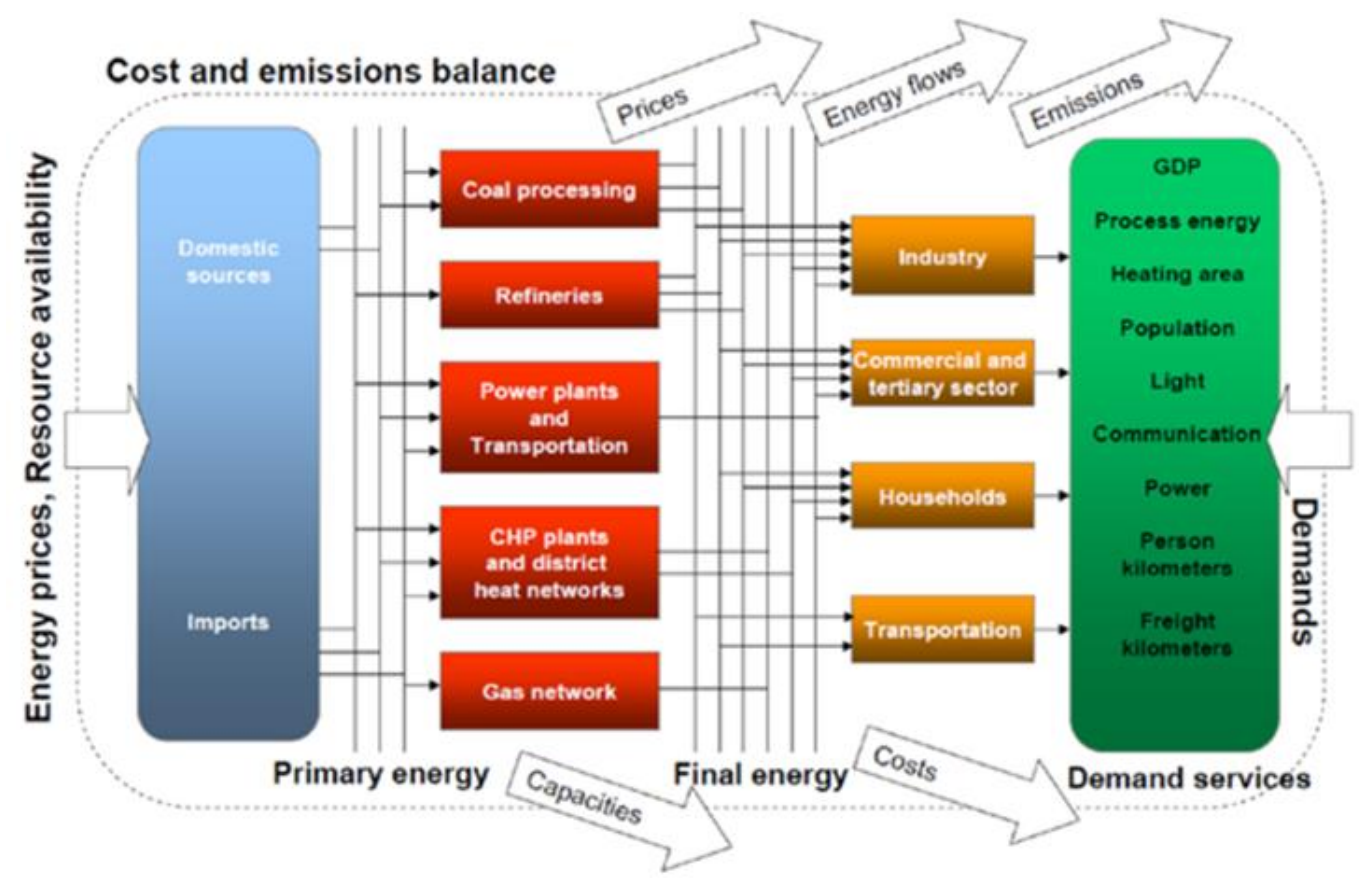

Figure 1. TIMES Model Schematic (Remme et al., 2001[7])

Figure 1 shows in schematic form how the TIMES model works. The core model includes a large energy supply-side and demand-side technology database. The model designs the best energy system to meet the demand of energy service at least cost in the whole time, and shows the best combination of technology and fuel, emission, mining and import activities and the equilibrium level of energy demand in each period.

Irish TIMES is a single regional model of the whole Irish energy system, which was originally extracted from Pan European TIMES (PET). It has been used to establish a series of energy and emission policies to explore the power behind the transfer to low-carbon energy system, analyze energy security [8], assess the impact of limited bioenergy resources [9], and explore new modelling methods [10]. However, its impact on the policy-making process was limited until 2013, when the Irish TIMES model was widely used in two key policy developments - the development of national legislation on climate change and the Ireland consult standpoint on the EU 2030 carbon and energy policy framework between June 2013 and September 2014.

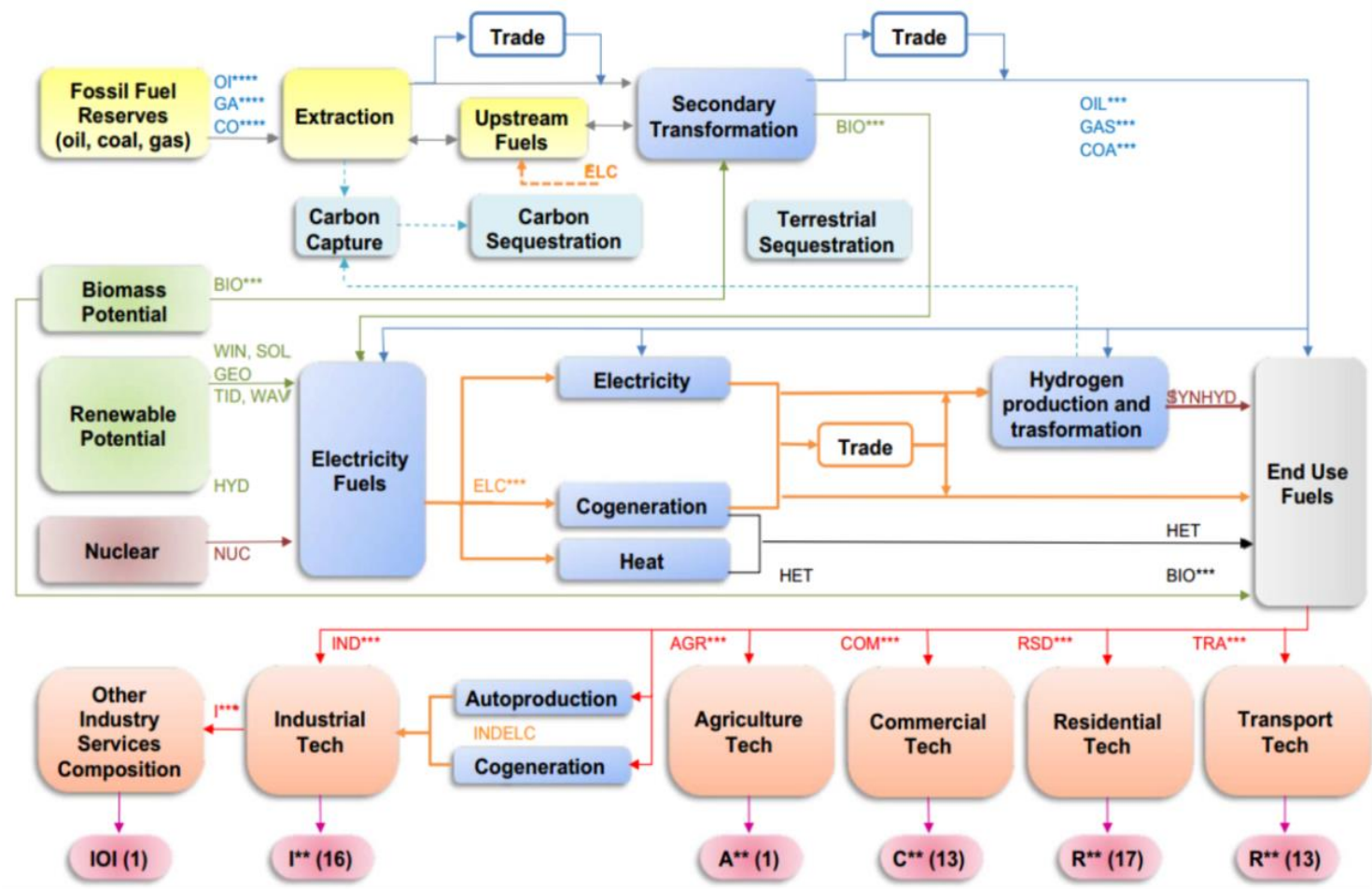

Figure 2. Irish TIMES Reference Energy System (Gargiulo et al., 2010[11]). 
The model is driven by exogenous demand as defined by the list of demand for each energy service, the actual value of the base year (calibration) and all milestone year values (forecast) up to 2050, as well as environmental or other constraints (such as Ireland and EU goals). More details can be found in the full Irish TIMES report [5].

\subsection{An approach for DPRK's GHG emission mitigation model}

DPR Korea has always attached great importance to environmental protection in constructing the socialist power. DPR Korea ratified the UNFCCC on 5 December 1994, the Kyoto Protocol on 27 April 2005 and the Paris Agreement on 1 August 2016. In accordance with decisions 1/CP.19, 1/CP.20 and 1/CP.21 of the Conference of the Parties to UNFCCC, the DPRK government decided to reduce GHG emissions by $8.0 \%$ by 2030 compared to the BAU scenario, and if additional international financial support, will increased up to $40.25 \%$ by $2030[1]$.

In this paper, we referred to the Irish TIMES energy system model, and the survey results of GHG inventory emitted from 1990 to 2002 in DPRK, and then studied a research methodology for DPRK's GHG emission mitigation model by 2030 . The model represents the energy system of DPRK and its possible long term evolution, and its applications are related to the analysis of polices designed to reduce GHGs from energy and materials consumption. It contains large database of energy supply side and demand side technologies.

As shown in Figure 3, the actual system model includes all steps from primary resource availability to energy service supply required by energy consumers, through the process chain of energy conversion, transportation, distribution and transformation into services.

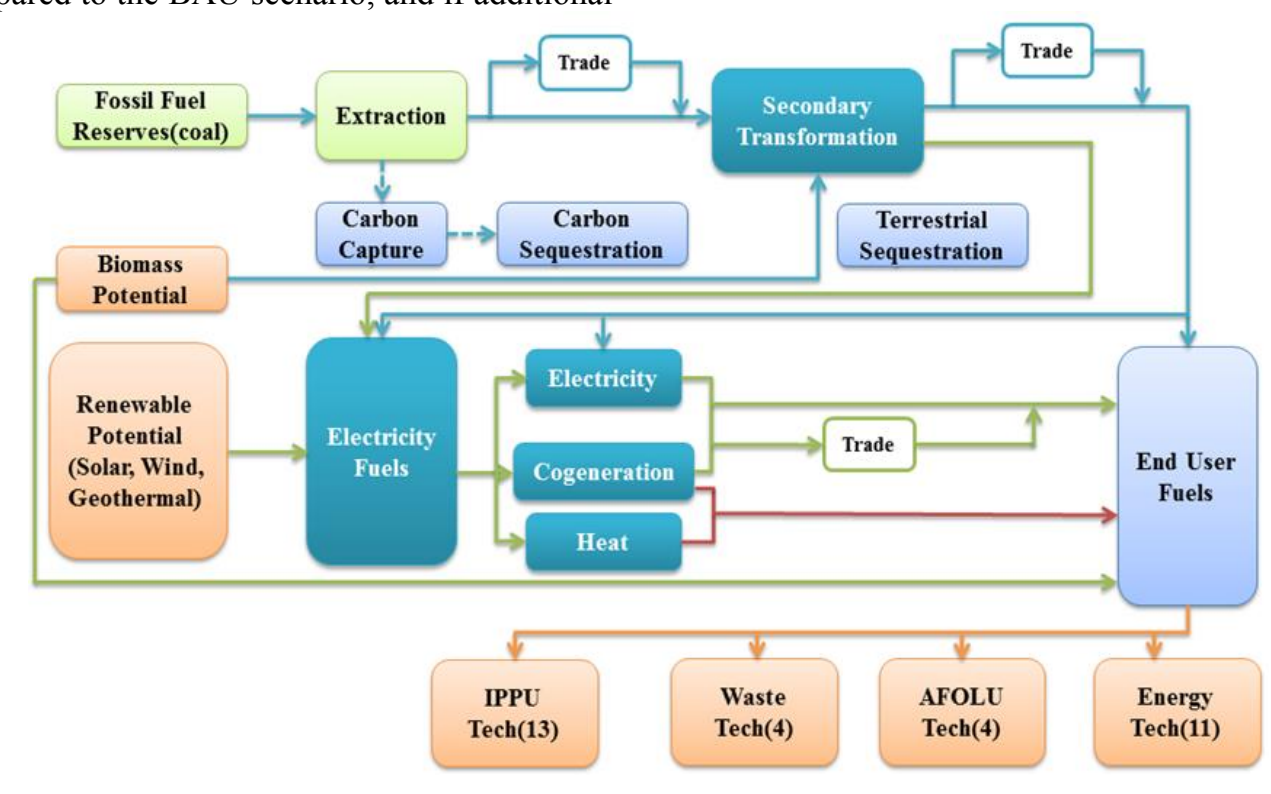

Figure 3. A reference model for Energy System in DPR Korea (the model's current focus is on GHG emissions)

The characteristics and patterns of DPRK's energy system are reflected in its supply sector (primary and secondary production, exogenous import), power generation sector (also including cogeneration) and demand sector such as energy, IPPU (Industrial Processes and Product Use), AFOLU (Agriculture, Forestry and Other Land Use), waste.

The key inputs to the DPRK's GHG emission mitigation model are the demand component (demand for energy services), the supply component (resource potential and costs), the policy component (scenarios) and the techno-economic component (alternative technologies and associated costs).

\subsubsection{Construction of Demand component}

The number of energy service demands can vary between different models and the level of detail of data available for each sector. In DPRK's GHG emission mitigation model, the demand component is driven by 32 different energy service demand (specified by the list in Table 2), namely 11 for the energy sector, 13 for IPPU, 4 for AFOLU, 4 for waste. Higher levels of detail are used in the energy sector, in which fuel combustion activities and fugitive emission from fuels are classified according to 11 different types. In IPPU sector, standard production chains have been used to design specific sectors such for example Cement and Iron and Steel. In AFOLU sector, anthropogenic GHG emissions and removals occurring on managed land where human interventions and practices have been applied to perform production, ecological or social functions should be estimated. Main emission/removal sources in AFOLU sector in the country are divided into 4 categories such as Livestock, Land, Aggregate Sources and Non-CO2 Emissions Sources on Land, other. Main GHG emission sources in waste sector are classified according to 4 types such as Solid Waste Disposal, Biological Treatment of Solid Waste and so on. 
Table 2. List of exogenous energy service demands in the DPRK's GHGs mitigation model.

\begin{tabular}{|c|c|c|c|c|c|}
\hline Code & Description & Unit(*) & Code & Description & Unit(*) \\
\hline & Energy(11) & & \multicolumn{3}{|c|}{ IPPU(13) } \\
\hline EAEHP & $\begin{array}{c}\text { Main Activity Electricity and } \\
\text { Heat Production }\end{array}$ & PJ & ICP & Cement Production & Mt \\
\hline EPRE & Petroleum Refining & PJ & ILP & Lime Production & Mt \\
\hline EIST & Iron and Steel & Mt & IOPUC & Other Process Uses of Carbonates & PJ \\
\hline ENFM & Non-Ferrous Metals & PJ & IAP & Ammonia Production & Mt \\
\hline ECHE & Chemicals & PJ & INAP & Nitric Acid Production & Mt \\
\hline EMAC & Machinery & PJ & ICP & Carbide Production & Mt \\
\hline EMQU & Mining and Quarrying & PJ & IPCBP & $\begin{array}{l}\text { Petrochemical and Carbon Black } \\
\text { Production }\end{array}$ & Mt \\
\hline ECON & Construction & PJ & IFCP & Fluorochemical Production & Mt \\
\hline ETRA & Transport & $\mathrm{Mt} * \mathrm{~km}$ & IISP & Iron and Steel Production & Mt \\
\hline EOSE & Other Sectors & PJ & IFP & Ferroalloys Production & Mt \\
\hline \multirow[t]{2}{*}{ EFEF } & $\begin{array}{l}\text { Fugitive Emissions from } \\
\text { Fuels }\end{array}$ & PJ & IAP & Aluminium Production & Mt \\
\hline & Waste(4) & & ILP & Lead Production & Mt \\
\hline WSWD & Solid Waste Disposal & PJ & IZP & Zinc Production & $\mathrm{Mt}$ \\
\hline WBTSW & $\begin{array}{c}\text { Biological Treatment of Solid } \\
\text { Waste }\end{array}$ & PJ & & AFOLU(4) & \\
\hline WIOBW & $\begin{array}{l}\text { Incineration and Open } \\
\text { Burning of Waste }\end{array}$ & PJ & ALS & Livestock & PJ \\
\hline \multirow[t]{3}{*}{ WWTD } & $\begin{array}{c}\text { Wastewater Treatment and } \\
\text { Discharge }\end{array}$ & PJ & $\mathrm{AL}$ & Land & PJ \\
\hline & & & ASNCES & $\begin{array}{l}\text { Aggregate Sources and Non- } \mathrm{CO}_{2} \\
\text { Emissions Sources on Land }\end{array}$ & PJ \\
\hline & & & $\mathrm{AO}$ & Other & PJ \\
\hline
\end{tabular}

$(*)$ PJ here means 'PJ of final energy in the base year'.

Projecting future energy service demands over the time horizon within DPRK's GHG emission mitigation model require two sets of parameters: demand drivers and elasticities. Both demand drivers (for example population, GDP) and demand elasticities are mostly linked to economic activity and to energy prices, which are usually exogenously obtained via other models or from accepted other sources. To drive the demand component in DPRK GHG emission mitigation model, this paper are used as demand drivers that are summarized in Table 3.

Demand drivers rates (DDR) and elasticities constitute the energy service demand driver (ESD Driver) over the period using the following formulas:

$$
\operatorname{DDR}(t)=\left(\left(\frac{\text { Demand Driver }(t)}{\text { Demand Driver }(t-1)}\right)-1\right)
$$

Table 3. Trends of demands drivers in the DPRK's GHGs mitigation model 1990-2030.

\begin{tabular}{ccccccccc}
\hline Driver & Description & $\begin{array}{c}1990- \\
1993(\%)\end{array}$ & $\begin{array}{c}1993- \\
1996(\%)\end{array}$ & $\begin{array}{c}1996- \\
2000(\%)\end{array}$ & $\begin{array}{c}2000- \\
2008(\%)\end{array}$ & $\begin{array}{c}2008- \\
2011(\%)\end{array}$ & $\begin{array}{c}2011- \\
2020(\%)\end{array}$ & $\begin{array}{c}2020- \\
2030(\%)\end{array}$ \\
\hline GDP & GDP & -1.4 & -38.6 & -17.1 & 59.4 & 30.5 & - & - \\
POP & Population & - & - & - & - & 0.018 & - & - \\
ENE & $\begin{array}{c}\text { Energy } \\
\text { sector }\end{array}$ & -12.5 & -57.3 & 10 & - & - & 34.3 & - \\
IPPU & IPPU sector & 5.87 & -47 & -63.7 & - & - & 58.8 & - \\
AFOLU & $\begin{array}{c}\text { AFOLU } \\
\text { sector }\end{array}$ & 4.2 & -12.2 & -26.3 & - & - & -40.9 & - \\
WASTE & $\begin{array}{c}\text { WASTE } \\
\text { sector }\end{array}$ & 1.3 & 4.6 & 3.1 & - & - & 14.8 & - \\
\hline
\end{tabular}




\subsubsection{Construction of Supply component}

A key input to DPRK's GHG emission mitigation model on the supply side is the present and future sources of primary energy supply their potentials and fuel prices.

Table 4. GHG abatement potentials and abatement costs for potential mitigation options up to 2030

\begin{tabular}{|c|c|c|c|c|}
\hline Sector & Option & Scenario & $\begin{array}{c}\text { Abatement } \\
\text { potential } \\
\left(\mathrm{GgCO}_{2} \mathrm{e} / \mathrm{yr}\right) \\
\end{array}$ & $\begin{array}{l}\text { Abatement } \\
\text { cost } \\
\left(\mathrm{US} \$ / \mathrm{tCO}_{2} \mathrm{e}\right) \\
\end{array}$ \\
\hline \multirow{6}{*}{$\begin{array}{l}\text { Energy } \\
\text { Supply }\end{array}$} & $\begin{array}{l}\text { Modernization of } \\
\text { existing thermal } \\
\text { power plants }(\mathrm{O} 1)\end{array}$ & $\begin{array}{l}\text { Coal saving through increasing by } 10 \% \\
\text { of efficiency of existing thermal power } \\
\text { plants with capacity of } 500 \mathrm{MW}\end{array}$ & 998 & -4.0 \\
\hline & $\begin{array}{l}\text { Coal mine methane } \\
\text { utilization and } \\
\text { destruction } \\
\text { programme }(\mathrm{O} 2)\end{array}$ & $\begin{array}{l}\text { Electricity and heat generation by } \\
\text { capturing coal mine methane in coal } \\
\text { mines (CDM project) }\end{array}$ & 715 & -9.0 \\
\hline & $\begin{array}{l}\text { Creation of new } \\
\text { hydropower } \\
\text { generation capacity } \\
\text { (O3) }\end{array}$ & $\begin{array}{l}\text { Creation of new hydropower generation } \\
\text { capacity of } 1,000 \mathrm{MW} \text { including } \\
\text { hydropower CDM projects }\end{array}$ & 6,985 & -14.1 \\
\hline & $\begin{array}{l}\text { Construction of solar } \\
\text { thermal power plants } \\
\text { (O4) }\end{array}$ & $\begin{array}{l}\text { Construction of solar thermal power } \\
\text { plants with capacity of 500MW } \\
\text { substituting for coal fired power plants } \\
\text { with capacity of } 200 \mathrm{MW}\end{array}$ & 1,597 & 30.2 \\
\hline & $\begin{array}{l}\text { Construction of wind } \\
\text { farms (O5) }\end{array}$ & $\begin{array}{c}\text { Construction of wind farms with } \\
\text { capacity of } 1,000 \mathrm{MW} \text { substituting for } \\
\text { coal fired power plants with capacity of } \\
\text { 300MW }\end{array}$ & 2,395 & 7.7 \\
\hline & $\begin{array}{l}\text { Construction of } \\
\text { atomic power station } \\
\text { (O6) }\end{array}$ & $\begin{array}{l}\text { Construction of atomic power station } \\
\text { with capacity of } 2,000 \mathrm{MW} \text { substituting } \\
\text { for coal fired power plants with same } \\
\text { capacity }\end{array}$ & 15,966 & 11.5 \\
\hline
\end{tabular}

Finally is worth nothing that all constraints designed

\subsubsection{Model sets and assumptions}

The DPRK's GHG emission mitigation model used here has a time horizon of 40 years that ranges from 1990, the base year, to 2030, with time resolution of four seasons with day-night time resolution.

The current DPRK's GHG emission mitigation model does not have an elastic demand module, therefore, the energy system can respond here to emissions constraints through energy efficiency and energy supply technology change but not through demand reduction.

The model also embeds several constraints to improve the realism associated with future energy pathways. In fact the intrinsic nature of a linear programming model could otherwise deliver in many cases extreme technology switches. Constraints are designed to take into account physical limitations such the lack of infrastructure. In addition, although the detailed modeling of transmission issues, frequency and inertia issues of voltage stability is not considered in this analysis, the constraints are set to reproduce the operation constraints in the power system. The model also includes a limited number of diffusion constraints to control the growth rate of certain sectors such electricity generation and IPPU sectors. in this model (excluding policy constraints described in Section 2.2.4 that characterize single scenarios) are applied in all scenarios, and no constraints are imposed to maintain systems until the end of their lifetime.

\subsubsection{Scenario definition}

For the purposes of this research work main energy system configuration have been developed and discussed in this paper: the BAU scenario, introduced to provide a starting point against which the two GHG emissions mitigation scenarios can be measured, namely the $\mathrm{CO} 2-8$ scenario, the CO2-40 scenario.

(a) DPR Korea's BAU scenario for GHG emissions was developed based on the assumption of economic growth in the absence of climate change policies. For the period to 2030 national energy forecasts are used as a benchmark [1]: it provides a starting point against which other scenarios are compared.

(b) In the CO2-8 scenario DPR Korea will reduce GHG emissions by $8.0 \%$ compared to BAU scenario, by 2030 with domestic resources.

(c) In the CO2-40 scenario DPR Korea could achieve the additional contribution equivalent to $40.25 \%$ of the GHG emission in the BAU scenario by 2030 if
Given the importance of renewable energy for the achievement of mitigation targets, DPRK's energy potentials and costs are based on the most recently available data (Table 4). 
international support is received through international cooperation including the financial support under the Paris Agreement.

\section{Results}

The DPRK's BAU scenario is compared with two alternative medium term(to 2030) energy pathways, one that delivers an $8 \%$ reduction in energy-related $\mathrm{CO} 2$ emissions (CO2-8) and another that delivers an $40.25 \%$ reduction in GHG emissions (CO2-40 i.e., 40.25\% reduction in $\mathrm{CO} 2$ emission assuming international financial support under the Paris Agreement). Figure 4 illustrates the trajectories of energy-related $\mathrm{CO} 2$ emissions for the BAU scenario and the constrained emissions mitigation scenarios $\mathrm{CO} 2-8$ and $\mathrm{CO} 2-40$. In the BAU scenario, emissions reach $187.73 \mathrm{Mt} \mathrm{CO} 2$ in 2030 , representing a $3 \%$ reduction relative to 1990 levels. In scenario $\mathrm{CO} 2-8$, the maximum $\mathrm{CO} 2$ emissions that the energy system can produce in 2030 are $172.73 \mathrm{Mt}$, representing a $10 \%$ reduction relative to 1990 levels. In scenario $\mathrm{CO} 2-40$, the maximum $\mathrm{CO} 2$ emissions that the energy system can produce in 2030 are $112.18 \mathrm{Mt}$, representing a $42 \%$ reduction relative to 1990 levels.

By the trends for GHG emissions, total national GHG emissions are projected to continue increasing after 2000 on for recovery of the national economy declined in the early 1990's. DPR Korea's GHG emission is $65.714 \mathrm{Mt}$ in 2000, which accounts for $0.16 \%$ of the World GHG emission in $2000(40,000 \mathrm{Mt})$. With the GHG emissions of $2.9 \mathrm{t}$ per capita in 2000, DPR Korea is one of low GHG emitting countries in terms of emissions per capita. GHG emission per capita will be increased to $6.5 \mathrm{t}$ in 2030 , but it will be still below the world average.

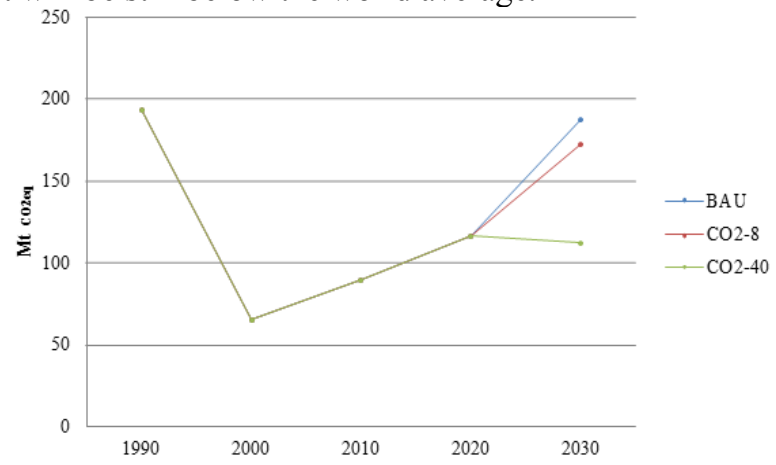

Figure 4. Total $\mathrm{CO} 2$ emission trajectories by scenario (Mt)
Figure 5 compares the breakdown of $\mathrm{CO} 2$ emission reductions by sector in 2030 for each of the mitigation scenarios. By 2020, the total national GHG emissions are projected to amount to $121.203 \mathrm{Mt}$, which is the decreased value by $37.4 \%$ compared with 1990 and the increased value by $84.4 \%$ compared with 2000 . For the period 2000-2020, annual average growth rate of total GHG emissions will account for $3.1 \%$. And, variation in proportion of energy, IPPU and AFOLU sector in the total national GHG emissions for the period 2000-2020 is projected to be insignificant. Attaining 2020, energy sector is projected to be the largest emission source, accounting for $89.0 \%$ of the total national $\mathrm{GHG}$ emissions without consideration of $\mathrm{CO} 2$ removals, and IPPU and waste sector to account for $10.1 \%$ and $0.9 \%$ respectively. For this period, GHG emissions from fuel combustion activities and fugitive emissions from fuels categories under energy sector are projected to increase $3.0 \%$ and $3.2 \%$ on annual average respectively. Attaining to 2020, GHG emissions from fuel combustion activities category are projected to amount to $119.756 \mathrm{Mt}$, accounting for $90.7 \%$ of the GHG emissions from energy sector. That is to say, fuel combustion activities category will be the most important emission source in DPRK in future.

Meanwhile, $\mathrm{CO} 2$ will be the GHG with the largest emission proportion in energy sector for the economic feature relying on domestic coal for the period 20002020 and $\mathrm{CO} 2$ emissions, through increasing by $3.0 \%$ on annual average, will amount to $116.707 \mathrm{Mt}$ in 2020 , accounting for $88.4 \%$ of the emissions from energy sector.

As mentioned above, if the GHG emissions of energy sector remains at similar levels to 2020, the energy system must deliver a $81.9 \%$ reduction in emissions (relative to 1990 levels) in order to reach an overall $8 \%$ GHG emissions reduction target (mainly focus on the CO2-8 scenario of GHG emissions with domestic resources) by 2030 .

In $\mathrm{CO} 2-8$ most of the emission reductions are achieved in energy and IPPU sector, with reductions, respectively of $14.2 \mathrm{Mt}$ and $2.1 \mathrm{Mt}$ relative to BAU scenario. To deliver the $8 \% \mathrm{CO} 2$ emissions reduction target, additional reductions are achieved in the AFOLU sector, with reductions of $41.3 \mathrm{Mt}$. According to the CO2-40 scenario, the reduction of GHGs in the energy and the IPPU sector is mostly reduced $61.2 \mathrm{Mt}$ and $9 \mathrm{Mt}$ respectively, and additional reductions in the AFOLU sector is $54.5 \mathrm{Mt}$. 


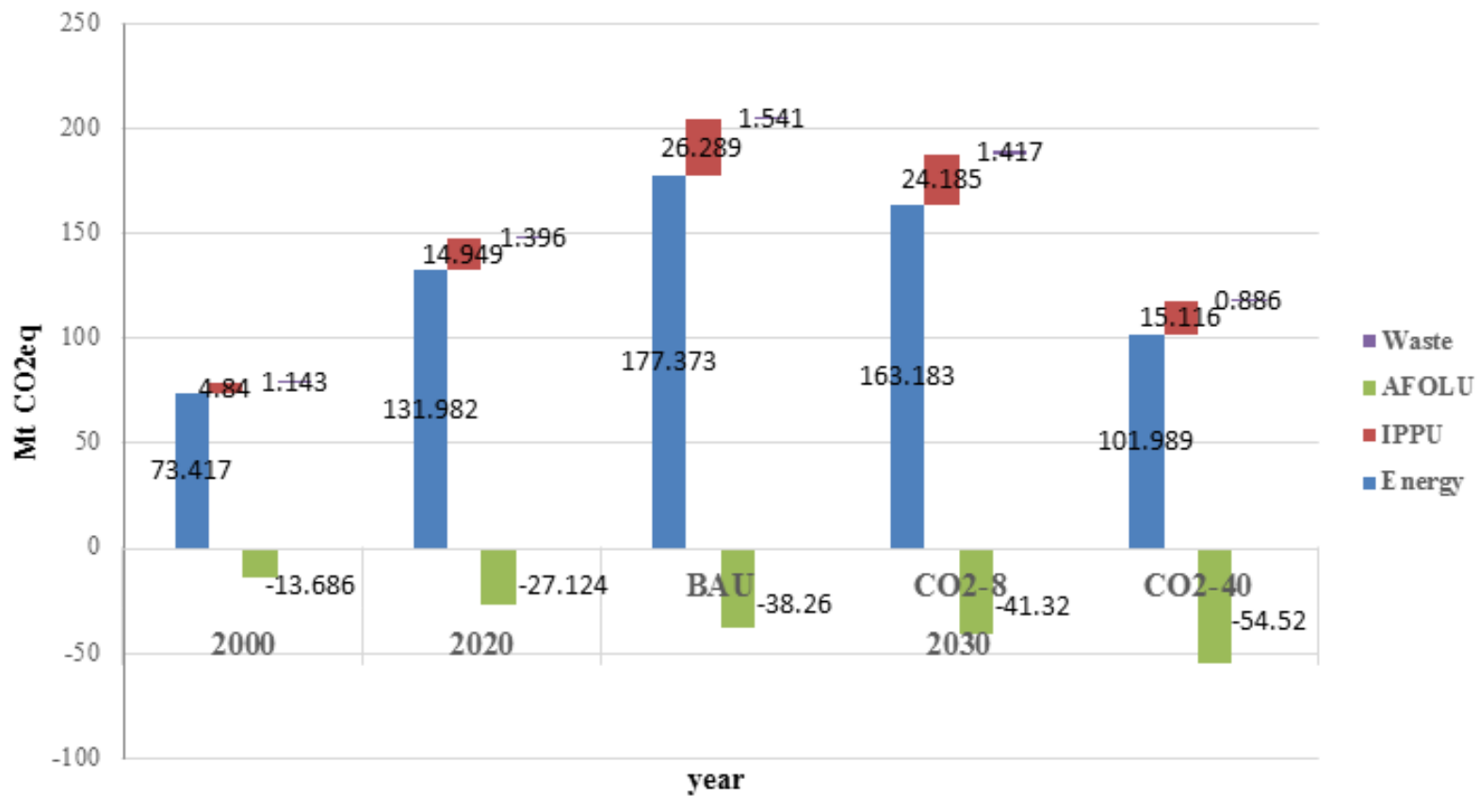

Figure 5. Decomposition of total $\mathrm{CO} 2$ emissions in $\mathrm{BAU}, \mathrm{CO} 2-8$ and $\mathrm{CO} 2-40$ scenarios (Mt).

The results of this paper is lacking because the institutional framework and capacity of organs for preparing GHG inventory are insufficient, and the data currently used are also insufficient and of high uncertainty, and there is a lack of subdivided activity data. However, in this paper, we proposed a research framework for the energy system and the possibility of providing technology that can reduce GHGs in DPR Korea.

\section{Conclusion}

This paper reports results on ambitious mitigation target to 2030 for the DPRK energy system. This paper analyzes the Irish TIMES model which is widely used in the analysis of the national energy policy model. Moreover, it have been performed using the DPRK's GHGs mitigation model which a cost optimizing linear programming energy systems model. This paper represents that challenging emissions reductions such as $8 \%$ and $40 \%$ relative to 1990 levels can be technically achieved in DPRK, and energy efficiency and renewable energy technologies will have a determining role to deliver the target at least cost. The paper also illustrates some initial impacts of short term targets and policies on the longer term mitigation pathway for DPRK's energy system. The applications of the model are related to the analysis of policies aimed to reduce GHG emissions from energy and materials consumption. The model will provide some help to the producers of DPRK's future energy polices and contribute to international activities related to reducing GHG emissions.

This presented model of the paper is very temporary and the initial model of DPRK's energy system. So, it will be completed through continuous learning process and simulation courses. In addition, it should be further completed through active academic assistance and exchanges with the international community. We will strive to ensure the clear theoretical basis of the model proposed in this paper and the better flexibility of the national energy system for economic development. Further analysis is required in this area and on the feedback between the energy system and the economy, to better assess the economic impacts of deep mitigation.

\section{References}

1. Intended Nationally Determined Contribution of Democratic People's Republic of Korea (INDC), 2016. http://www.unfccc.int/ndcregistry/PublishedDocuments/ Democratic\%20People\%27s\%20Republic\%20of\%20K orea\%20First/DPRK-INDC\%20by\%202030.pdf

2. SC Johnson College, GLOBAL INNOVATION INDEX 2018, pp.22

3. Trinity College Library Dublin (2001) Renewable Energy in Ireland: Law, Policy and Practice, pp. 39

4. DPR Korea's Second National Communication on Climate Change, 2012, pp. 50-59, 115, 121

5. Ó Gallachóir BP, Chiodi A, Gargiulo M, Deane P, Lavigne D, Rout UK (2012) Irish TIMES energy systems model. EPA climate change research programme 2007-2013. Report Series No. 24. UCC, Johnstown Castle, Co.Wexford. http://erc.epa.ie/safer/reports

6. https://iea-etsap.org/index.php/etsap-tools/modelgenerators/times

7. Remme U., Goldstein G.A., Schellmann U., Schlenzig C., 2001 MESAP/TIMES - advanced decision support for energy and environmental planning, In P. Chamoni, R. Leisten, A. Martin, J. Minnemann, H. Stadtler (Eds.), Operations Research Proceedings 2001. Selected Papers of the International Conference on Operations Research (OR 2001), 3-5 September, Springer, Duisburg, Germany (2001), pp. 59-66 
8. Glynn J, Chiodi A, Gargiulo M, Deane JP, Bazilian M, Gallachóir BÓ (2014) Energy security analysis: the case of constrained oil supply for Ireland. Energy Policy 66(0):312-325.

doi:

http://dx.doi.org/10.1016/j.enpol.2013.11.043

9. Chiodi A, Deane P, Gargiulo M, Ó Gallachóir BP (2015a) The role of bioenergy in Ireland's low carbon future is it sustainable. J Sustain Dev Energy, Water and Environment Systems 3(2):196-216

10. Deane JP, Chiodi A, Gargiulo M, Gallachóir BPÓ (2012) Soft-linking of a power systems model to an energy systems model. Energy 42(1):303-312. doi: http://dx.doi.org/10.1016/j.energy.2012.03.052

11. Gargiulo M., Kanudia A., Loulou R., Giannakis G., Tosato G., 2010 Application of the Pan-European TIMES Model, Proc 11th IAEE European Conference, 25-28 August, Vilnius, Lithuania.

12. Loulou, R., Remme, U., Kanudia, A., Lehtila, A., Goldstein, G., 2005. Documentation for the TIMES Model, Energy Technology Systems Analysis Programme (ETSAP). Available from: http://www.etsap.org/documentation.aspS. 